\title{
Periodic Price Reduction as a Way to Boost Diminishing Demand
}

Wen Zhou*

School of Business, the University of Hong Kong, Pokfulam Road, Hong Kong

\begin{abstract}
In this paper, I offer a new theory for why price reductions take place on a regular basis in some industries. I suggest that the demand for a firm's product drops over time because of the erosion of consumers' brand recall, and that price discounts are utilized to boost the diminishing demand. A dynamic model is then constructed to demonstrate the theory for both monopoly and duopoly competition. I show that it is optimal for a monopolist to alternate between a constant high (normal) price and a constant low (discount) price with fixed frequency, and that competing firms offer discounts at the same time in duopoly competition.
\end{abstract}

Keywords: Price discounts; Intertemporal pricing; Dynamic oligopoly; Dynamic programming; Shifting demand

\section{Introduction}

Price discounts are pervasive in the business world. At the retailing level, various forms of price reductions exist for various reasons. This paper focuses on a particular form of price discounts, namely a periodic price reduction that consists of long periods of a constant (high) price and short periods of a discounted (low) price. This kind of intertemporal pricing is typical in the fast food and service industries. For a time in Durham, North Carolina, all Burger King Customers could enjoy burgers at $\$ 0.99$ a piece on Wednesdays, while the normal price was $\$ 2.99$. More interestingly, during that same time, Wendy's also offered its price discounts every Wednesday. Another example is the discount price of HK \$40 that all movie theatres in Hong Kong simultaneously charge on Tuesdays, vis-a-vis a regular ticket price of HK $\$ 60$ on any other days. Free admission is available each Wednesday in all public museums in Hong Kong. ${ }^{1}$. In many European countries, public transportation is free on particular days each year. Similar pricing patterns exist for durable goods. Figure 1 shows the daily price time path of color TVs at Sears, San Diego [1].

Existing literature has several explanations for why price discounts are offered. Some models focus on spatial price dispersion, while some others study price variations over time. Spatial price dispersion cannot persist unless there is market friction, otherwise a store charging a higher price than its competitors would not have any sales. Market friction, in the form of consumer searching costs or switching costs, typically leads to mixed strategy equilibria, which generates intertemporal price variation for any given store [2-4]. The variation, however, does not display any regularity. Price discounts on selected items may serve the purpose of generating store traffic. The familiar marketing tactic of the "loss leader" or the "bait and switch" strategy is meant to use the low price of one good to lure consumers into buying the complements [5,6] or substitutes [7] for that good. However, fast food restaurants and movie cinemas are both highly specialized stores that would find it difficult to offer a great variety of complements and substitutes.

More relevant to this paper are models with a clear time dimension.

${ }^{1}$ Weekly discounts seem to be most common, but other frequencies exist. A museum in Los Angeles, California, lets people in free of charge on the first Tuesday of each month.

${ }^{2}$ Here the discrimination takes the form of inventory shifting. Another possible scenario is to use inter temporal price variation to sort consumers with differentia valuations of the product. But, as pointed out by Stokey [14] and Varian [15], this practice is in general not profitable.

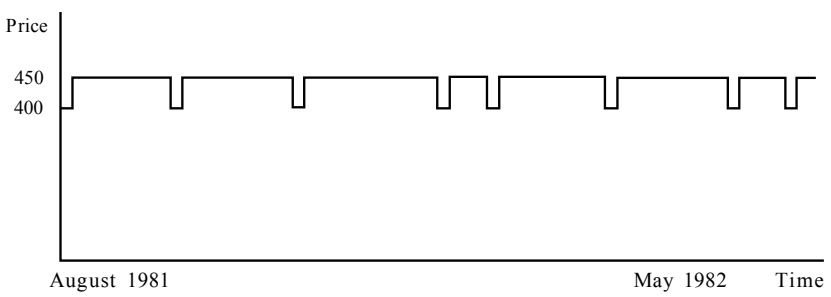

Figure 1: Daily price time path of color TVs at Sears, San Diego [1].

Lazear [8] suggests that in the presence of demand uncertainty, a good strategy is to start with a high price and eventually lower the price if the item has not been sold. While Lazear's model explains well the "clearance sale" of fashion clothing, for which demand uncertainty plays a central role, it is hardly applicable to generic goods such as fast foods, for which demand is relatively predictable. Besides, an auctiontype downward pricing is quite different from a cyclic price movement. Intertemporal price discrimination could happen when consumers have differential costs for holding inventories ${ }^{2}$, which makes periodic price discounts optimal $[9,10]$.

But, obviously, people do not buy large amounts of fast food to save for future consumption. Fast food, like services, is not storable. Finally, price discounts could be a store's optimal response to a changing demand or cost. In Conlisk et al. [11], Sobel [12], and Pesendorfer [13], a new cohort of consumers enters the market each period so that cyclic pricing is optimal for the firms. These models are mainly suitable for durable goods: Once a consumer buys the good, she vanishes forever from the market; if a consumer does not buy at some time, she stays in the market until the next sale. Clearly, fast foods are not durable. It is also hard to believe there are new customers who enter the market every day.

*Corresponding author: Wen Zhou, School of Business, the University of Hong Kong, Pokfulam Road, Hong Kong, E-mail: wzhou@business.hku.hk

Received February 03, 2012; Accepted April 21, 2012; Published April 23, 2012

Citation: Zhou W (2012) Periodic Price Reduction as a Way to Boost Diminishing Demand. J Bus Fin Aff 1:102. doi:10.4172/2167-0234.1000102

Copyright: ( 2012 Zhou W. This is an open-access article distributed under the terms of the Creative Commons Attribution License, which permits unrestricted use, distribution, and reproduction in any medium, provided the original author and source are credited. 
In this paper, I am interested in the regular intertemporal price movement of a non-durable, non-storable good exemplified by fast food and other industries. There is clearly a cycle: a store charges a constant regular price most of the time, and a constant discounted price every now and then. The timing of discounts is fixed and predictable, and the pricing pattern exists in both monopoly and oligopoly, with all stores offering discounts at the same time ${ }^{3}$. In this paper, I offer a new theory for why price reductions take place on a regular basis. A dynamic model is then constructed to show that the pricing pattern observed in reality is indeed optimal for the firms.

When people think of periodic price reductions such as those by Burger King and Wendy's on Wednesdays, the first response might be "peak-load pricing" such as the "Happy Hours" studied by Varian [15], the seasonal price variation described by Gerstner [16], or the well-known pricing pattern for electricity, car rentals, telephone calls, etc. in which fixed capacity plays an important role. Presumably, the mid-week demand for dining (or movie) services is smaller than that during weekends, which justifies differential and cyclic prices. It is then optimal for a monopolist to charge a low price in the mid-week when demand is low. But, then, why does the price reduction not appear on Tuesdays or Thursdays? It is hard to believe that the demand stays the same for six days of the week, and then sharply drops on Wednesdays, as implied by a discount price of $\$ 0.99$ versus a normal price of $\$ 2.99$. A more fundamental problem with this explanation, though, is the requirement of market power. When there is competition, peak-load pricing is simply not sustainable. In fact, Warner and Barsky [17] document strong empirical evidence of lower prices when demand is higher, for example, during weekends and holidays.

Another plausible explanation for periodic price reduction is intertemporal price discrimination-high valuation consumer's purchase on the spot, while price-sensitive customers wait until the price is lowered ${ }^{4}$. In order for them to make intertemporal choices, however, consumers need to have unit demand each week, not every day. While this might be true for movies and video tape rentals, it is hardly the case with fast food or mass transportation, for which people make daily purchases. One more problem with the price discrimination theory is that it cannot explain why the seller offers the good for free (e.g. museums and European mass transportation). Price discrimination is meant to raise profits. A zero price is obviously not optimal if price discrimination is the only purpose: the seller would have been better off closing the business on that day rather than offering the product or service for free.

In summary, I believe the existing literature is not able to explain fully the price cycles in the fast food and other industries. I attempt to give a new explanation for the phenomenon in this paper. My argument consists of two major points. First, without any stimulation, the demand for a particular product diminishes over time, as consumers eventually forget about this product. A person might not remember the good taste of a Big Mac if there is nothing to remind her, so she just brings her lunch from home. In fact, a declining demand is one of the major reasons behind the need for continuous and endless advertising. Why does Nike repeatedly promote itself? Why because otherwise people will go away. A new product may need advertising to inform people of its existence and of the function of the product, or to signal its quality [18], but for well-established brand names such as McDonald's, Nike or Intel, persistent advertising campaigns can only be explained by one purpose: keeping consumers hooked. Without any reminder, a firm's consumer base will gradually erode away. The second point of my argument is that periodic price discounts can be used to boost diminishing demands. A price reduction will certainly lead to a higher quantity demanded in the current period. But a higher current consumption implies a higher demand in the future. This positive relationship has been well established in the habit persistence literature [21-24]. If a consumer's utility is a function of past consumption as well as current consumption, then the marginal utility of current consumption, and hence the demand function, would be increasing in past consumption. Blattberg and Neslin [25] point out: "... any purchase of a brand has implications beyond the immediate purchase occasion: The consumer forms a habit toward purchasing the brand, sustains that habit, or learns about the performance of the brand". Slade [26] expresses a similar idea in her empirical formulation of price changes. The demand function in her model contains a term for consumer goodwill, which erodes over time and reacts positively to price cuts.

Given the basic idea of a shrinking demand and the possibility for a firm to use price discounts to boost the demand, I study the optimal and equilibrium choice of price discounts under both monopoly and duopoly settings. In the model, firms have a large set of choice variables at their disposal: the normal and discount prices as well as the duration, frequency, and timing of discounts. I find that it is indeed optimal for firms to offer a constant normal (high) price most of the time, and a constant discounted (low) price occasionally with the same frequency. In duopoly equilibrium, each firm seeks the longest lasting effect of its boosted demand before the demand is eroded by its rival's next discount. As a result, in equilibrium, the two firms offer discounts at the same time.

It has been well established in consumer psychology [27] and social psychology [28] literature that consumers' memory declines over time and the memory can be stimulated by sales promotions such as price discounts. For example, Wyer's [27] Principle 2 states that "The accessibility of a unit of knowledge in memory is an increasing function of both the recency with which it has been activated and the frequency with which it has been activated. The effect of recency decreases over time." Adaval and Monroe [29] demonstrated the relation between knowledge accessibility and pricing. Nedungadi [30] found that changes in a brand's accessibility may affect the probability that it is retrieved and considered for choice. Alba and Chattopadhyay [31] demonstrated that consumers have difficulties recalling brands (brand inhibition), and that exposure to promotion activities induces positive responses from consumers. "Frequent or recent exposure to a brand increases its salience (i.e., the prominence or 'level of activation' of a brand in memory), thereby increasing the ability of a consumer to recall it. Marketing variables that enhance the salience of a brand have been shown to be related directly to recall."

Banerjee [32,33] presented two models to explain how people are influenced by others' opinions. Behavioral learning theory suggests that rewarded behavior tend to persist [34,35]. Promotions such as price discounts can serve as such a reward, thereby increasing subsequent purchases. Boulding et al. [36], Mela et al. [37], Papatla and Krishnamurthi [38], Shankar and Krishnamurthi [39] all found that promotion purchasing changes price sensitivity. Gedenk and Neslin [40] demonstrated that promotion had long-term effects on consumer

${ }^{3}$ Doyle [19] claims that "most stores seem to hold sales simultaneously".

${ }^{4} \mathrm{~A}$ slightly different story is offered by Villas-Boas [20]: Consumers live for two periods. A monopolist firm price discriminates against consumers who have bought in the previous period. Cyclical pricing occurs in equilibrium. 
behavior. Price promotions have been demonstrated to be profitable in the long run $[41,42]$. Sellers usually employ two types of promotion tactics [43]: A flat, low price (everyday low pricing), and an alternation between a relatively high price and frequent price discounts (hi-lo pricing). Tsiros and Hardesty [44] have suggested a new discounting strategy, which requires a seller to return the discounted price to the regular level in several steps rather than at once. They argue that consumers will be tricked into purchasing more because they observe an upward time trend of the price and may conclude that the price will keep rising. To the extent that word of mouth (WOM) or consumer and professional reviews help establish a positive relation between present consumption and future consumption, these channels are consistent with the theory presented here. I have mainly used the habit persistence theory to explain the positive relation, but WOM and reviews will lead to the same prediction. Of course WOM and reviews will mainly affect the consumption choice by potential buyers rather than existing buyers, but at the aggregate level they would still lead to a positive relation. Marketing scholars have long established the importance of WOM and reviews. The advance of the internet has made it much easier to collect and quantify such information [45-51]. Many firms regard online consumer reviews as an important marketing tool [52]. They regularly post product information and sponsor promotional chats on online forums [53], and may even manipulate online reviews [54].

The paper is organized as follows. The basic monopoly model is set up in Section 2. The next three sections study the optimal choice of the normal price and the depths and frequency of discounts. Section 6 extends the basic model to duopoly competition and derives the equilibrium timing of discounts. Finally, Section 7 concludes the paper.

\section{The Model: Monopoly}

Time is discrete with an infinite horizon. A time unit is called a period. Consider a monopolist who sells a standard product in each period. Consumers are distributed uniformly with density 1 along a straight line, one end of which is occupied by the monopolist firm. In each period, every consumer demands at most one unit of the product. Consumers' willingness to pay is $\mu$, and the unit transportation cost in period $t$ is $\left(1 / x_{t}\right)$ for all consumers. In period $t$, the marginal consumer, who is in different between buying and not buying, is therefore characterized by $\mu-p_{t}-\left(1 / x_{t}\right) \omega_{t}=0$, where $p_{t}$ is the price in that period and $\omega_{t}$ is the distance between the consumer and the firm. This equation leads to $\omega_{t}=x_{t}\left(\mu-p_{t}\right)$. A consumer buys from the firm if and only if he is located between the firm and the marginal consumer. As a result, the quantity demanded for the monopolist in period $t, q_{t}$ is represented by the marginal consumer's location in that period: $q_{t}=\omega_{t}$ (recall that the distribution density is 1$)$. That is, the demand function for the firm in period $t$ is $q_{t}=x_{t}\left(\mu-p_{t}\right)$.

The unit transportation cost, $1 / x_{t}$, represents the difficulty consumers have in remembering the product. An obscured memory means a higher transportation cost, or, equivalently, a lower $x_{t}$. In a way, $x_{t}$ can be interpreted as the stock of consumer memory or goodwill. As argued before, this memory should erode over time and respond positively to price cuts. More specifically,

\section{Assumption 1}

The consumer memory, $\mathrm{x}_{\mathrm{t}}$, changes in the following way: given $\mathrm{x}_{\mathrm{t}-1}$ in the previous period and the depth of the price discount, $d_{t}$, in the current period,

$$
\mathrm{x}_{\mathrm{t}}=\delta \mathrm{x}_{\mathrm{t}-1}+\lambda \mathrm{d}_{\mathrm{t}}
$$

Where $0<\delta<1, \lambda>0$ the depth of the discount, $\mathrm{d}_{\mathrm{t}}$, is defined as

$$
\mathrm{d}_{\mathrm{t}}=\max \left\{\mathrm{r}_{\mathrm{t}}-\mathrm{p}_{\mathrm{t}}, 0\right\} \text {, }
$$

Where $\mathrm{p}_{\mathrm{t}}$ is the actual price charged in period $t$ and $\mathrm{r}_{\mathrm{t}}$ is the reference price for that period.

Assumption 1 describes the transition of consumer memory between two consecutive periods. The memory erodes at a fixed rate, $\delta$, and can be boosted by $\lambda$ for every dollar of price cuts ${ }^{5}$. For simplicity, the effect of price discounts on $x_{t}$ is assumed to be linear and is separable from that of $\mathrm{x}_{\mathrm{t}-1}$. This assumption can be relaxed without changing the basic features of the model ${ }^{6}$.

The monopolist is said to offer a price discount in period $t$ if the actual price, $p_{t}$, is strictly lower than the reference price, $r_{t}$. Otherwise, the price is normal $\left(p_{t} \geq r_{t}\right)$. The depth of the discount, $d_{t}$ is defined to be the difference between $r_{t}$ and $p_{t}$. When the firm charges the normal price, $d_{t}=0^{7}$.

\section{Assumption 2}

The reference price in period $t$ is

$$
\mathrm{r}_{\mathrm{t}}=\min \left\{\mathrm{p}_{\mathrm{r}}, \mathrm{p}_{\mathrm{t}-1}\right\}
$$

where $\mathrm{p}_{\mathrm{r}}$ is the long-term regular price, which is obtained by taking the average of normal prices over a long time span.

Consumers determine their reference price in period $t, r_{t}$, as the lower value between the price in the previous period, $\mathrm{p}_{\mathrm{t}-1}$, and the longterm regular price, $\mathrm{p}_{\mathrm{r}}$. They will not be fooled by two possible tricks used by the firm. On the one hand, there is a general regular price, $p_{r}$. The firm is not able to cheat by raising $\mathrm{p}_{\mathrm{t}-1}$, charging a $\mathrm{p}_{\mathrm{t}}$ that is lower than $\mathrm{p}_{\mathrm{t}-1}$, and then claiming that it is having a "discount" in period t. On the other hand, consumers have fresh memory about the price in the previous period. They do not think any price that is lower than the regular price is always a discount ${ }^{8}$. The demand is not stimulated if today's price is higher than or equal to yesterday's price, even if both are lower than the regular price. In other words, a lower price is thought to constitute a discount only when it is lower than both the long-term regular price, $\mathrm{p}_{\mathrm{r}}$, and the last period price, $\mathrm{p}_{\mathrm{t}-1}$.

Consumers take the average of "normal" prices to form the longterm regular price, $\mathrm{p}_{\mathrm{r}}$. It should be emphasized that the average is taken over non-discount prices, not the price in every period. For example, $\$ 2.99$ is both the long-term regular price of a burger and the "normal" price that is charged each day except Wednesdays. Consumers have a

${ }^{5}$ The fixed percentage drop in memory should be more realistic than a fixed absolute drop: $x_{t}=x_{t-1}-\delta+\lambda d_{t}$, where there is nothing to prevent the memory stock from dropping below zero.

${ }^{6}$ A more general specification is to let $x_{t}$ asymptotically approach a certain level, say, $x_{0}$. That is, $x_{t}=x_{0}+\left[\delta\left(x_{t-1}-x_{0}\right)+\lambda d_{t}\right]$ with $x_{t} \geq x_{0}$ for every $t$. The model presented in this paper is a special case where $x_{0}=0$.

${ }^{7}$ That is to say, the effect of price changes on the position of the demand function is asymmetric: a price reduction shifts out the demand curve, while a price rise does not have the opposite effect. This is because people have clear perceptions about normal and discount prices: a two dollar price cut is welcomed by everybody, while moving back to $\$ 2.99$ is interpreted as only "returning to the normal price."

${ }^{8}$ This can also be understood from the angle of reputation. As part of brand equity, reputation may be adversely affected by price discounts because low prices may deliver the image of low quality [55]. 
clear understanding that $\$ 0.99$ is a discount price and should not be included when they determine the long-term regular price 9

Finally, the firm is assumed to have a constant marginal production cost, $c \in(0, \mu)$; a fixed cost, $F$, in the discount period (the cost of, say, advertising and changing price tags); and a time discount factor, $\beta \in$ $(0,1)$. The monopolist chooses the price in each period to maximize the total present value of profit.

\section{Normal Prices and Long-Term Regular Price}

We first determine the optimal choice of normal prices. A normal price, $p_{t}$, (i.e., no discount is offered in this period) affects the firm's objective function directly and indirectly. The direct effect is on the current-period profit, while the indirect effect is on the next-period profit through the formation of the reference price ${ }^{10}$. The profit of period $t$ is $\pi_{t}=q_{t}\left(p_{t}-c\right)=x_{t}\left(\mu-p_{t}\right)\left(p_{t}-c\right)$. Since $d_{t}=0$, the coefficient $x_{t}$ $=\delta x_{t-1}+\lambda d_{t}=\delta x_{t-1}$ is not affected by the choice of $p_{t}$. Then, the singleperiod profit, $\pi_{t^{\prime}}$, is maximized at the monopoly price, $p_{m}=(\mu+c) / 2$, which does not depend on the time index, $t$. Therefore, although the demand changes over time, the change is in such a way that the single period profit is maximized at the same price. When prices deviate from this optimal level, $\pi_{t}$ monotonically increases in $\mathrm{p}_{t}$ when $\mathrm{p}_{\mathrm{t}}<\mathrm{p}_{\mathrm{m}}$ and monotonically decreases in $p_{t}$ when $p_{t}>p_{m}$.

For the indirect effect, because $r_{t+1}=\min \left\{p_{r}, p_{t}\right\}$, the current price $\mathrm{p}_{\mathrm{t}}$, can become the reference price for the next period. This is relevant only when a discount is offered in $t+1$. We can show that the indirect effect does not distort normal prices from $\mathrm{p}_{\mathrm{m}}$.

\section{Therefore,}

Proposition 1: In equilibrium, every normal price is the same, and they all equal $\mathrm{p}_{\mathrm{m}}=(\mu+\mathrm{c}) / 2$. Consequently, the long-term regular price is $\mathrm{p}_{\mathrm{r}}=\mathrm{p}_{\mathrm{m}}=(\mu+\mathrm{c}) / 2$.

The driving force behind the uniform pricing in normal periods is that the single period monopoly price is the same despite changing demand coefficients. One may think that a uniform normal price that is slightly higher than $\mathrm{p}_{\mathrm{m}}$ should be beneficial to the firm, as a higher reference price means a smaller distortion in the discounted periods. This is not true, because when there are two consecutive normal periods, the optimal price for the first period should be $\mathrm{p}_{\mathrm{m}}$, as it does not have any direct or indirect effect on the next period profit.

Proposition 1 greatly simplifies the firm's choice: When it is not offering any discount, the firm should always charge the same normal price. Nevertheless, the firm still faces complicated choices: the duration of discounts (i.e., whether or not it wants several consecutive discounts), the depth of every discount, and the frequency of discounts.

\section{Depth of Discount}

For a wide range of parameter values, it can be shown that the firm should choose at most one discount period between any two must be lower than the preceding price in order to constitute a discount. If the preceding price is already discounted, offering a further discount in the next period would be more costly, as the price would be farther away from the single-period-profit-maximizing price. Most of the time, the firm would rather wait for at least one period after a discount before the next is offered.

In principle, the firm has the freedom of never offering any discounts, but in most cases this is not optimal ${ }^{12}$. Basically, the cost of offering a discount includes the fixed cost, $F$, and a lower current profit, while the benefit is higher demands in the future. If, the firm never offers any discount, the demand would eventually drop to zero, in which case offering discounts at least once is beneficial, given that the fixed cost, $F$, is not prohibitively high.

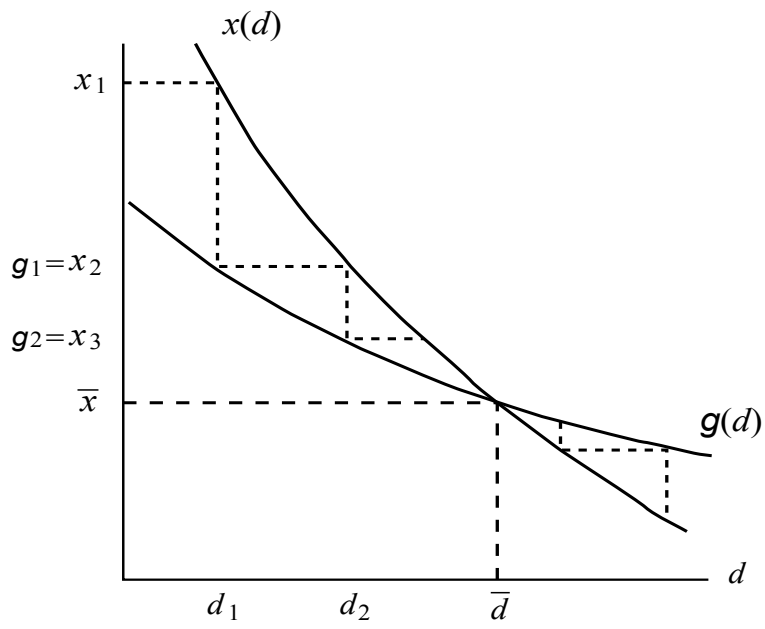

Case 1: $g^{\prime}\left(d_{m}\right)<0$

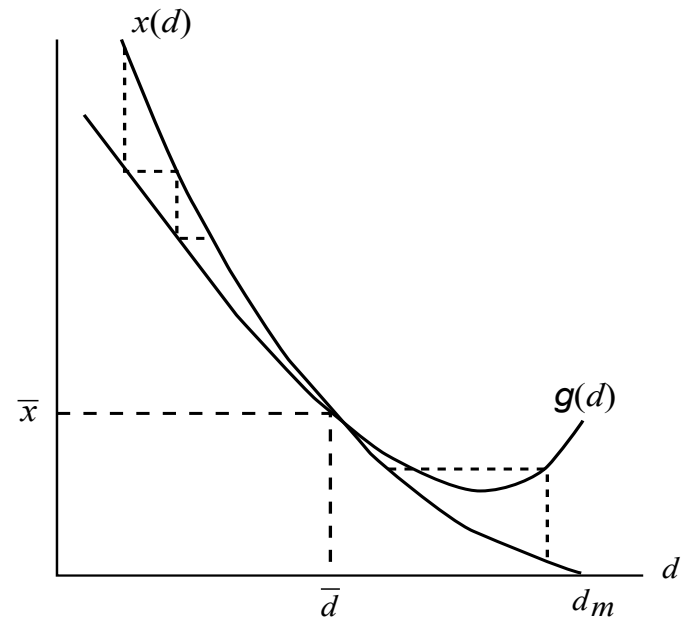

Case 2: $g^{\prime}\left(d_{m}\right)>0$

Figure 2: The dynamic transition of the demand coefficient.

${ }^{9}$ Blattberg and Neslin [25] present empirical findings on how the long-term regular price is formed: if the current price differs substantially from the normal price, then the observed price will be seen as "exceptional" and the regular price will not be updated. "This essentially tells the consumers that the reduced price is temporary and should not be used to decrease the consumers reference price" (p.46). I should point out that the "reference price" in Blattberg and Neslin [25] is in fact the "Iong-term regular price" in this paper.

${ }^{10} \mathrm{In}$ principle, there could be a third effect: the firm's profit may be affected by normal prices through a change in the long-term regular price, $\mathrm{p}_{\mathrm{r}}$, which is the average of normal prices. The average, however, is taken over a long time span, so the impact of a single normal price on pr is negligible.

${ }^{11}$ The sufficient condition is that $z$ or $F$ is large enough, where $z=(\mu-c) / 2$, or that both $\delta$ and $\beta$ are close enough to 1 .

${ }^{12}$ The necessary condition for never offering any discount is $F>\left(\lambda \beta \delta z^{3}\right) /(1-\beta \delta)$. 
It now becomes clear that the firm's optimal strategy is to offer price discounts once at a time: a price discount for one period, then a normal price for several periods, followed by another discount for one period, and several other normal periods, and so on and so forth. I call the price movement from one discount period to the next a cycle. Consider the case when exactly $\mathrm{n}$ periods form a cycle. The firm chooses $n$ first, commits to it, and then chooses the depth of the discount in each cycle. In what follows, I will determine the optimal depth of the discount for any given $\mathrm{n}$, discuss the stability of the system, and finally find the optimal $n$. Making $\mathrm{n}$ a parameter first and then a choice variable implies that the discounts must be offered at equal pace ${ }^{13}$.

A cycle starts with $(n-1)$ periods of normal prices and ends with a discount price, after which a new cycle starts. Suppose that the demand coefficient is $\mathrm{x}$ when a cycle starts, and that the depth of the discount is $d$. Then, $x_{t}=\delta^{t-1} x$ for $t=1,2, \cdots, n-1$ and $x_{n}=\delta^{n-1} x+\lambda d$. By Proposition 1, for $t=1,2, \cdots, n-1, p_{t}=p_{m}$. The present value of profit is thus $\pi_{t}=x_{t}\left(\mu-p_{t}\right)\left(p_{t}-c\right)=\delta^{t-1} x^{2}$, where $z=(\mu-c) / 2$ is the profit margin when $p_{m}$ is charged. In the last period, $p_{n}=p_{m}-d$, which means that $\pi_{n}=x_{n}\left(\mu-p_{n}\right)\left(p_{n}-c\right)-F=\left(\delta^{n-1} x+\lambda d\right)\left(z^{2}-d^{2}\right)-F$. The total present value of the profits in the cycle is:

$$
\pi(x, d)=\sum_{t=1}^{n} \beta^{t-1} \pi_{t}=x y+\beta^{n-1}\left[\lambda d\left(z^{2}-d^{2}\right)-\delta^{n-1} x d^{2}-F\right] \text { (2) }
$$

Where $y=\frac{z^{2}\left(1-\beta^{n} \delta^{n}\right)}{1-\beta \delta}>0$ at the beginning of the next cycle, $\mathrm{x}_{\mathrm{n}+1}=\delta \mathrm{x}_{\mathrm{n}}=\delta^{\mathrm{n}} \mathrm{x}+\delta \lambda \mathrm{d}$.

\section{Optimal depth of discount}

Starting from an arbitrary $\mathrm{x}$, the monopolist chooses a series of $\mathrm{d}$ in each cycle in order to maximize lifetime profits. This is a typical dynamic programming problem. In each cycle, there is a state variable, $\mathrm{x}_{\mathrm{i}}$, and a choice variable, $\mathrm{d}_{\mathrm{i}}$. The time subscript has been changed from $\mathrm{t}$ to $i$, as the index is now about cycles (each consisting of $n$ periods), not periods. The transition equation is

$$
\mathrm{x}_{\mathrm{i}+1}=\delta^{\mathrm{n}} \mathrm{x}_{\mathrm{i}}+\delta \lambda \mathrm{d}_{\mathrm{i}}
$$

In line with standard procedures (see, for example, Stokey and Lucas, 1989) [56], define the value function as $\mathrm{V}(\mathrm{x})$. Then the value function satisfies the following Bellman equation:

$$
V(x)=\max _{0<d \leq p_{m}}\left\{\pi(x, d)+\beta^{n} V\left(\delta^{n} x+\delta \lambda d\right)\right\}
$$

Where the profit of the current cycle, $\pi$, is given by equation (2). A unique optimal choice, $\mathrm{d}>0$, is found for any given initial demand, $\mathrm{x}$ :

\section{Proposition 2: The optimal choice of discount, $\mathrm{d}$, is given by:}

(i) $d=d^{*}=\frac{x \phi-\sqrt{x^{2} \phi^{2}-\lambda^{2} \varphi y}}{\lambda \varphi}$ if $x^{2} \geq\left(\varphi \lambda^{2} y\right) / \phi^{2}$

(ii) $d=p_{m}=\frac{\mu+c}{2}$ if $x^{2}<\left(\varphi \lambda^{2} y\right) / \phi^{2}$, where

$\phi=\delta^{n-1}\left(1-\beta^{n} \delta^{2 n}\right)>0, \varphi=2 \beta^{n} \delta^{n}+2 \beta^{n} \delta^{2 n}-3$

A discount brings the following tradeoff: a positive $d$ deviates from $\mathrm{pm}$, reducing the profit in the current period; but it also boosts consumers' brand recall, increasing the demand in the future. At $d=0$, the first effect is zero, so the second effect dominates.

Therefore, unless $\lambda=0$, the discount, $d$, should always be positive: the firm should always offer discounts.

It is easy to verify the following comparative static properties:

$$
\frac{\partial d^{*}}{\partial x}<0, \frac{\partial d^{*}}{\partial z}>0, \frac{\partial d^{*}}{\partial \lambda}>0, \frac{\partial d^{*}}{\partial \delta}>0, \frac{\partial d^{*}}{\partial \beta}>0
$$

These signs all make intuitive sense: the discount should be deeper when the current business is not very good, a normal price brings more profit, consumers are more sensitive to price discounts, the decline in consumer goodwill is slower, or the firm is more patient.

\section{Stability of the dynamic system}

Proposition 2 determines the optimal depth of discounts. For any given $\mathrm{x}$, there is a corresponding optimal choice, $\mathrm{d}^{*}(\mathrm{x})$. Then, given $\mathrm{d}^{*}$, at the beginning of the next cycle, the firm faces a new demand, $g=\delta^{n} x$ $+\delta \lambda \mathrm{d}^{*}(\mathrm{x})$, and needs to make another choice of $\mathrm{d}$. We are interested in the stability of the dynamic system, namely whether or not such choices of $\mathrm{d}^{*}$ will eventually lead to any steady state. It will make no sense to talk about price discounts if the system explodes.

The stability of the dynamic system can be studied in the following way ${ }^{14}$. Express both $\mathrm{x}$ and $\mathrm{g}$ as functions of the optimal discount, $\mathrm{d}^{*}$. It can be shown that the two functions have a unique intersection, which, by definition, is the steady state. Both functions are decreasing in $\mathrm{d}^{\star}$ at the intersection, and $\mathrm{x}$ is always steeper than $\mathrm{g}$. Moreover, $\mathrm{x}$ decreases in $\mathrm{d}^{\star}$ over the entire range, while $\mathrm{g}$ can be either monotonically decreasing in $\mathrm{d}^{*}$ (case 1 in Figure 2, where $\mathrm{dm}$ is the largest value that $\mathrm{d}^{*}$ can take) or U-shaped (case 2 in Figure 2). Thus, the transition from $x$ to $g$ is determined by using $\mathrm{d}^{*}$ as a linkage. In either case, it is obvious from Figure 2 that starting from any $\mathrm{x}$, the system converges monotonically toward the steady state. Therefore, we have

\begin{tabular}{|c|c|c|c|c|c|c|c|c|c|c|c|}
\hline $\mathrm{x}$ & 100 & 74.69 & 56.47 & 43.54 & 34.57 & 28.53 & 24.59 & 22.12 & 20.60 & 19.69 \\
\hline $\mathrm{d}$ & 1.24 & 1.65 & 2.14 & 2.70 & 3.28 & 3.81 & 4.25 & 4.57 & 4.79 & 4.93 \\
\hline $\mathrm{x}$ & 0 & 9.72 & 13.77 & 15.83 & 16.95 & 17.58 & 17.94 & 18.14 & 18.26 & 18.32 \\
\hline $\mathrm{d}$ & 10.24 & 6.97 & 6.01 & 5.60 & 5.39 & 5.28 & 5.22 & 5.18 & 5.16 & 5.15 \\
\hline
\end{tabular}

Table 1: Time paths of demands and discounts under monopoly.

\begin{tabular}{|l|l|l|l|}
\hline & $\bar{d}$ & $\bar{x}$ & $\bar{\pi}$ \\
\hline$z$ & + & + & + \\
\hline
\end{tabular}

Table 2: Comparative statics in the steady state.

${ }^{13}$ There are two justifications for this implication. First, there may exist some natural choices of n, e.g. once a week. Once every other week or twice a week will be too confusing for consumers to remember. Second, the firm may need to announce and commit to the frequency of discounts. Presumably, prices can change much quicker than the frequency of discounts. The model regards price as a short-term variable and frequency as a long-term one.

${ }^{14} A$ ccording to standard mathematics textbooks, the dynamic system is stable if and only if the eigenvalue of $g(x)=\delta^{n} x+\delta \lambda d^{*}(x)$ is less than 1 in absolute value. However, $d^{*}$ as a function of $x$ is very complicated, making it impossible to find the eigenvalue of $g(x)$. 
Proposition 3: The dynamic system (3) is globally stable: Starting from any $\mathrm{x}$, the system converges monotonically to a unique steady state in which

$$
x=\bar{x}=\lambda \delta z \sqrt{\frac{\gamma}{1-\delta^{n}}}, d=\bar{d}=z \sqrt{\gamma\left(1-\delta^{n}\right)}
$$

and $\gamma=\frac{1-\beta^{n} \delta^{n}}{(1-\beta \delta)\left(3-\delta^{n}-2 \beta^{n} \delta^{n}\right)}>0$

To give an idea of how the system evolves a numerical example is constructed as follows. Let $\lambda=1, \mathrm{z}=5, \delta=\beta=0.95, \mathrm{n}=6$. Then, the steady state is given by $\bar{x}=18.41, \bar{d}=5.13$. Starting from any $\mathrm{x}$ that is either above or below $\bar{x}$, the system, described by the state variable $\mathrm{x}$ and the choice variable $\mathrm{d}$, converges quickly and monotonically towards the steady state (Table 1).

The steady states of $\mathrm{x}$ and $\mathrm{d}$ are given in Proposition 3. By plugging them into equation (2), we can determine the profit of one cycle in the steady state. To simplify, assume $\beta=\delta$. Let $\mathrm{s}=\beta^{\mathrm{n}}=\delta^{\mathrm{n}}$, then,

$$
\bar{x}=\frac{\lambda \delta z}{\sqrt{1-\delta^{2}}} \sqrt{\frac{1+s}{(1-s)(3+2 s)}}, \bar{d}=\frac{z}{\sqrt{1-\delta^{2}}} \sqrt{\frac{1-s^{2}}{3+2 s}},
$$

and the profit of one cycle in the steady state is:

$$
\bar{\pi}=\frac{2 \lambda z^{3}}{\delta \sqrt{\left(1-\delta^{2}\right)^{3}}} \sqrt{\frac{(1-s)(1+s)^{5}}{(3+2 s)^{3}}}-\frac{s}{\delta} F
$$
Table 2.

$\lambda$ indicates the effectiveness of a discount on the demand. Previous discussion has shown that, for fixed $\mathrm{x}, \mathrm{d}^{*}$ increases in $\lambda$. However, when $\mathrm{d}$ increases, the demand coefficient of the next cycle increases so that $\mathrm{d}$ of the next cycle should be lower. The net effect happens to be that the steady state, $\bar{d}$, does not depend on $\lambda^{15}$.

\section{Frequency of Discounts}

Having analyzed the optimal choice of the discount in each cycle and the dynamics of the system for fixed $n$, I now turn to the optimal choice of $n$, which represents the frequency of discounts. In the steady state, the present value of lifetime profits is

$$
\Pi(n)=\frac{\bar{\pi}(n)}{1-\beta^{n}}
$$

Because $\beta=\delta$ and $s=\beta^{\mathrm{n}}=\delta^{\mathrm{n}}$, the profit becomes a function of $\mathrm{s}$ :

$$
\Pi(S)=\frac{1}{\delta}\left\{\frac{2 \lambda z^{3}}{\sqrt{\left(1-\delta^{2}\right)^{3}}} \sqrt{\frac{(1+s)^{5}}{(1-s)(3+2 s)^{3}}}-\frac{s F}{1-s}\right\}
$$

For fixed $\beta$ and $\delta$, choosing $n$ is equivalent to choosing $s \in(0,1)$.

Intuitively, the fixed cost, $F$, should play a crucial role in determining the optimal frequency of the discount. As shown previously, the optimal depth of the discount is positive when $F$ is not taken into account: the seller should offer the discount whenever she has a chance ${ }^{16}$. At the other extreme, when $F$ is extremely high, the firm may never want any discount. When $F$ takes a moderate value, there should be an interior solution of $n$.
Proposition 4: The optimal $\mathrm{n}^{\star}$ is found as follows: for $G=\frac{\lambda z^{3}}{\sqrt{\left(1-\delta^{2}\right)^{3}}}$

(i) when $\mathrm{F}>0.385 \mathrm{G}, \mathrm{n}^{*}$ is infinite (i.e., the firm should never offer any discount);

(ii) when $\mathrm{Gu}\left(\delta^{2}\right) \leq \mathrm{F} \leq 0.385 \mathrm{G}$, an interior $\mathrm{n}^{*}$ is found at $n^{*}=\frac{\ln s^{*}}{\ln \delta}$, , where

$u(s)=\left(6-s^{2}\right) \sqrt{\frac{(1+s)^{3}(1-s)}{(3+2 s)^{5}}}$ and $s^{*}$ satisfies $\mathrm{F}=\mathrm{Gu}\left(\mathrm{s}^{*}\right)$

(iii) when $\mathrm{F}<\mathrm{Gu}\left(\delta^{2}\right), \mathrm{n}^{*}=2$.

(iv) The interior solution, $\mathrm{n}^{\star}$, have the following properties:

$$
\frac{\partial n^{*}}{\partial F}>0, \frac{\partial n^{*}}{\partial z}<0, \frac{\partial n^{*}}{\partial \lambda}<0
$$

The sign of the comparative statics is quite intuitive. When the fixed cost is higher, discounts should be offered less frequently. When either $\lambda$ is larger (a discount is more effective in boosting demand) or $\mathrm{z}$ is larger (a higher demand is more profitable), the firm should offer discounts more often.

\section{Dynamic Duopoly Competition}

\section{Modification of the model}

The analysis so far has dealt with monopoly. Naturally, we would like to extend the model to oligopoly, where several firms compete by using price discounts. In addition to the depths and frequencies of discounts, the timing becomes a central issue: do the firms offer discounts at the same time? I focus on duopoly. To accommodate the interaction between firms, I modify the model as follows.

Two firms, designated a and $b$, sell differentiated products. The demand of firm i in period $\mathrm{t}$ is $q_{t}^{i}=x_{t}^{i}\left(\mu-p_{t}^{i}\right)$ where $\mathrm{i}=\mathrm{a}, \mathrm{b}$, and $p_{t}^{i}$ and $x_{t}^{i}$ are the price and demand coefficient of firm i in period t. The interaction between the two firms is assumed to affect only the demand coefficient:

$$
x_{t}^{i}=\delta x_{t-1}^{i}+\lambda d_{t}^{i}-\theta d_{t}^{j}
$$

where $0<\delta<1, \lambda>\theta \geq 0, \mathrm{j}=\{\mathrm{a}, \mathrm{b}\} \backslash \mathrm{i}$, and $d_{t}^{i}$ is firm i's depth of discount in period t. As in the model for monopoly, $d_{t}^{i}>0$ if firm i offers a discount in period $\mathrm{t}$, and $d_{t}^{i}=0$ if the normal price is charged.
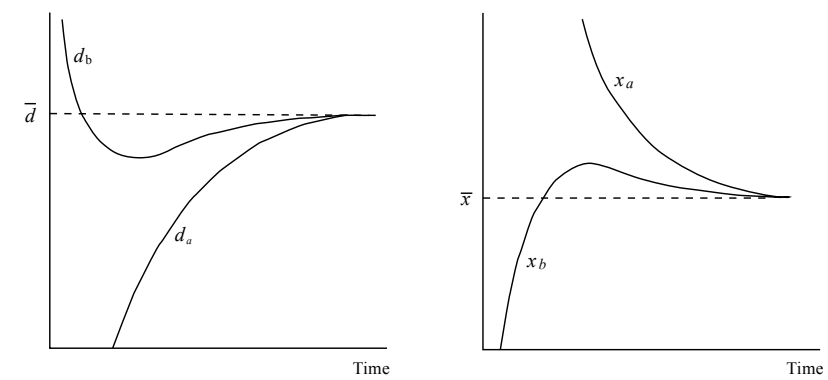

Figure 3: Firm b overshoots when firm a's starting demand is very high and firm b's is very low.

${ }^{15}$ This conclusion is sensitive to the specification of the model. For example, if $x_{t}$ drops asymptotically to a level, $x_{0}$, that is greater than zero (see footnote 5 ), then $\bar{d}$ will depend on $\lambda$.

${ }^{16}$ This argument is similar to that of the cash-in-advance model, where an individual must balance the cost of fore gone interest on the one hand, which is a variable cost, and the cost of making a trip to the bank on the other hand, which is a fixed cost. 
Compared to the monopoly case, there is now a new parameter, $\theta$, that captures the interaction between the two firms. When $\theta>0$, a firm's discount boosts consumer memory for its own product but hurts the memory for its rival's product. When $\theta=0$, the two firms become two independent monopolists.

Expression (7) says that, if neither of the firms offers any discount, the demand for each firm shrinks at a constant rate, $\delta$, but the lost consumers do not go to the firm's competitor. When a firm offers a discount, the demands of both firms are affected: the discounting firm's own demand is raised by a factor $\lambda$, while its rival's demand is reduced by a factor $\theta$. The rival's demand is affected because some of its customers are lured away by the discount ${ }^{17}$. Finally, when both firms offer discounts at the same time, the net effect will depend on the magnitude of the two discounts. Because $\lambda>\theta$, if the two discounts have the same depth, demands of both firms are boosted.

Since the interaction between the two firms only affects the demand coefficients, as in the case of monopoly, the normal prices should always be fixed at $\mathrm{p}_{\mathrm{m}}=(\mu+\mathrm{c}) / 2$ for each firm, and the profit of a normal period is $\pi_{t}^{i}=x_{t}^{i}\left(\mu-p_{t}^{i}\right)\left(p_{t}^{i}-c\right)=x_{t}^{i} z^{2}$, where, again $\mathrm{z}=$ $(\mu-c) / 2$ is the profit margin.

Under duopoly competition, I am primarily interested in the equilibrium timing of discounts, i.e., whether the two firms synchronize their offerings of discounts. This question is meaningful only when the frequency of discounting is the same for the two firms. As such, let us assume that both firms offer discounts once every n periods, which form a cycle. The game is played in two stages. In the first stage, the two firms announce simultaneously the timing of their discounts in each cycle. Given the fixed timing, in the second stage, the two firms choose the depths of discounts cycle by cycle.

\section{Second stage: The dynamic duopoly system with fixed timing}

As usual, the equilibrium is solved by backward induction, starting from the second stage. In the second stage, the firms' discounts may be simultaneous or non-simultaneous. Let us look at the two situations in turn.

Simultaneous timing: Without loss of generality, let the simultaneous timing occur at the beginning of each cycle. Suppose that the demand coefficients at the beginning of a cycle are $x_{a}$ and $x_{b}$ for the two firms and that the depths of the discounts are $d_{a}$ and $d_{b}$. Then, the two firms' profits from that cycle are:

$$
\pi_{a}=\left(x_{a}+\lambda d_{a}-\theta d_{b}\right)\left(y-d_{a}^{2}\right) ; \pi_{b}=\left(x_{b}+\lambda d_{b}-\theta d_{a}\right)\left(y-d_{b}^{2}\right)
$$

where, again, $y=\frac{z^{2}\left(1-\beta^{n} \delta^{n}\right)}{1-\beta \delta}$. Given $\mathrm{d}_{\mathrm{b}}$, firm a chooses $\mathrm{d}_{\mathrm{a}}$ to maximize its own lifetime profits. Likewise for firm b. The duopoly dynamic programming problem is thus set up as:

$$
\begin{aligned}
& V\left(x_{a}, x_{b}\right)=\max _{d_{a} \geq 0}\left\{\pi_{a}+\beta^{n} V\left(g_{a}, g_{b}\right)\right\} \\
& U\left(x_{a}, x_{b}\right)=\max _{d_{b} \geq 0}\left\{\pi_{b}+\beta^{n} U\left(g_{a}, g_{b}\right)\right\}
\end{aligned}
$$

There are two state variables, $\mathrm{x}_{\mathrm{a}}$ and $\mathrm{x}_{\mathrm{b}}$, and a choice variable for each firm. The transition equations of the system are given by:

$g_{a}=\delta^{n}\left(x_{a}+\lambda d_{a}-\theta d_{b}\right)$, and $g_{b}=\delta^{n}\left(x_{b}+\lambda d_{b}-\theta d_{a}\right)$

The best response function for each firm is found by dynamic programming ${ }^{18}$.

Lemma 1: In the subgame with simultaneous timing, the depths of discounts in each cycle are characterized by
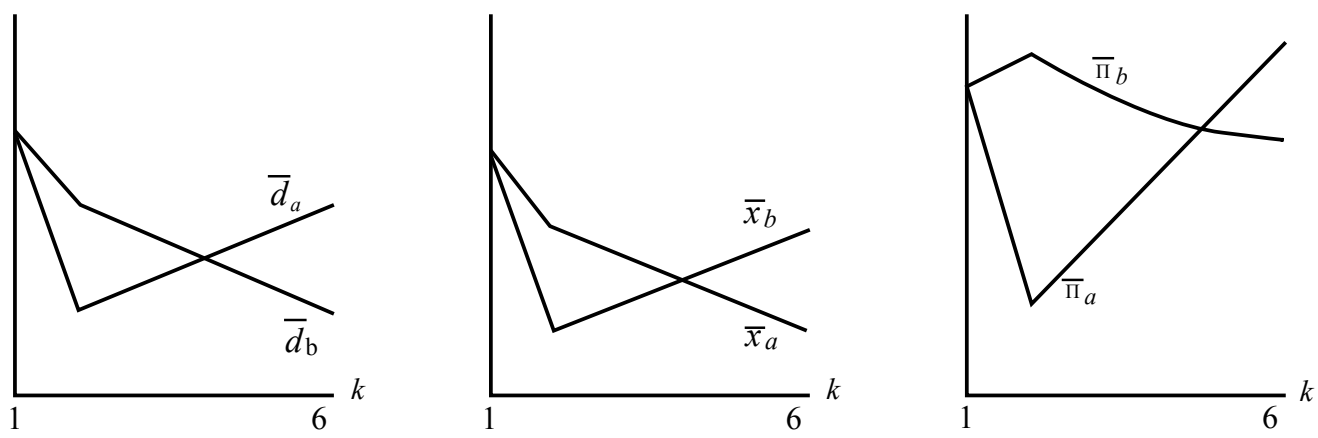

Figure 4: Steady state variables with different timing.

\begin{tabular}{|l|l|l|l|l|l|}
\hline $\mathrm{k}_{\mathrm{a}} \mathrm{k}_{\mathrm{b}}$ & 1 & 2 & 3 & 4 & 5 \\
\hline 1 & 926,926 & 802,944 & 842,922 & 879,906 & 913,898 \\
\hline 2 & 944,802 & 944,944 & 816,968 & 852,951 & 886,942 \\
\hline 3 & 922,842 & 968,816 & 963,963 & 833,994 & 865,983 \\
\hline 4 & 906,879 & 951,852 & 994,833 & 985,985 & 851,1022 \\
\hline 5 & 898,913 & 942,886 & 1022,851 & 1010,1010 \\
\hline 6 & 896,945 & 939,916 & 983,865 & 1018,880 & 1053,989 \\
\hline
\end{tabular}

Table 3: Steady state profits for various timing combinations.

${ }^{17}$ Basically, consumers evaluate the relative attractiveness of the two products when at least one firm is offering a discount. This is similar in spirit to the demand pattern of Rosenthal [57]: consumers start to compare the two products only when one firm raises its price. In my model, the interaction between the two firms is not through price or quantity (i.e., it is not Bertrand or Cournot), but rather through price reductions. There is implicitly an optimization problem that consumers solve, and expression (7) can be viewed as a reduced form of the demand due to consumers' choices. 


$$
\left\{\begin{array}{l}
\lambda \varphi d_{a}^{2}+2 \theta \eta d_{a} d_{b}-2 \rho x_{a} d_{a}+\lambda y=0, \\
\lambda \varphi d_{b}^{2}+2 \theta \eta d_{a} d_{b}-2 \rho x_{b} d_{b}+\lambda y=0,
\end{array}\right.
$$

where $\rho=1-\beta^{\mathrm{n}} \delta^{2 \mathrm{n}}, \phi=2 \beta^{\mathrm{n}} \delta^{\mathrm{n}}+2 \beta^{\mathrm{n}} \delta^{2 \mathrm{n}}-3$, and $\eta=1-\beta^{\mathrm{n}} \delta^{\mathrm{n}}-\beta^{\mathrm{n}} \delta^{2 \mathrm{n}}$

If the two firms' businesses are equally good (i.e., $x_{a}=x_{b}=x$ ), their discounts are of the same magnitude. Moreover, the common choice, $\mathrm{d}$ $\left(=d_{a}^{*}=d_{b}^{*}\right)$, have the following properties:

$$
\begin{aligned}
& \frac{\partial d}{\partial x}<0, \frac{\partial d}{\partial z}>0, \frac{\partial d}{\partial \delta}>0, \frac{\partial d}{\partial \beta}>0, \text { while } \\
& \frac{\partial d}{\partial \theta}>0 \text { if and only if } \beta^{n} \delta^{n}+\beta^{n} \delta^{2 n}<1
\end{aligned}
$$

These signs are quite intuitive and are also consistent with the corresponding signs under monopoly. There is a new parameter, $\theta$, under duopoly. For a large range of parameters, the depth of the discount, $d$, increases in $\theta$. That is, if a firm's customers are sensitive to the rival product's discounts, the firm should discount deeply so as to win back the leaving customers ${ }^{19}$.

Numerical examples show that starting from any pair of $\mathrm{x}_{\mathrm{a}}$ and $\mathrm{x}_{\mathrm{b}}$, the dynamic system converges to a unique steady state. The path of the convergence, however, is not necessarily monotonic. If $\mathrm{x}$ and $\mathrm{x}_{\mathrm{b}}$ differ very much, the firm that starts with a lower demand may overshoot in terms of both the choice variable, $d$, and the state variable, $\mathrm{x}$, before finally settling down at the steady state. Figure 3 illustrates this overshooting behavior. In this example, the parameter values are the same as in monopoly: $\lambda=1, \mathrm{z}=5, \delta=\beta=0.95, \mathrm{n}=6$, with a new parameter, $\theta=0.5$. The steady state is found to be $\bar{x}_{a}=\bar{x}_{b}=9.11$ and $\bar{d}_{a}=\bar{d}_{b}=6.56$. Firm a starts from $x_{a}^{0}=100$ while firm b starts from $x_{b}^{0}=0$.

The overshooting can be understood as follows. Due to its original high demand, firm a's discount is first very small and then eventually rises. In principle, firm b should do just the opposite: decrease the depths of its discounts over time. Under duopoly competition, however, there is interaction between the two firms. In the first several cycles, because firm a's discounts are small, there is not much interaction, so firm b continues to decrease its discounts. Later, the interaction becomes stronger, which requires $d_{a}$ and $d_{b}$ to move in the same direction, so the discount depths both go up. This gives rise to firm b's overshooting behavior.

Proposition 5: In the subgame with simultaneous timing, starting from any pair of $\mathrm{x}_{\mathrm{a}}$ and $\mathrm{x}_{\mathrm{b}}$, the dynamic system converges to a unique steady state in which

$$
\bar{x}_{a}=\bar{x}_{b}=\bar{x}=\frac{\delta^{n}(\lambda-\theta)}{\sqrt{1-\delta^{n}}} \sqrt{\frac{\lambda y}{\sigma}} \text { and } \bar{d}_{a}=\bar{d}_{b}=\bar{d}=\sqrt{\frac{\lambda y\left(1-\delta^{n}\right)}{\sigma}}
$$

where $\sigma=\lambda\left(3-\delta^{n}-2 \beta^{n} \delta^{n}\right)-2 \theta\left(1-\beta^{n} \delta^{n}\right)$
When the two firms start from different demand levels, the firm with the higher demand will choose a smaller discount, leading to a smaller difference between the two firms' demands in the next cycle. Eventually they converge to the same level.

\section{Non-simultaneous timing}

Now consider the case when the two firms offer discounts at different times. Without loss of generality, let firm a discount in the first period of each cycle and firm $\mathrm{b}$ in the $k$ th period, $2 \leq k \leq \mathrm{n}$. Following the same procedure as in the simultaneous timing case, it can be shown that the equilibrium depths of discounts, $\mathrm{d}_{\mathrm{a}}$ and $\mathrm{d}_{\mathrm{b}}$, are characterized by the following two best response functions: ${ }^{20}$

$$
\begin{aligned}
& \lambda \varphi d_{a}^{2}-2 \theta \beta^{n} \delta^{2 n-k+1} d_{a} d_{b}-2 \rho x_{a} d_{a}+\lambda y=0 \\
& \lambda \varphi d_{b}^{2}+2 \theta \eta \delta^{k-1} d_{a} d_{b}-2 \delta^{k-1} \rho x_{b} d_{b}+\lambda y=0
\end{aligned}
$$

where $\varphi, \rho$ and $\eta$ are defined in Lemma 1 .

Numerical examples show that, for every timing arrangement, the duopoly dynamic system is globally stable and converges to a unique steady state. Figure 4 shows the two firms' steady state discounts, demands in the discount period, and per-cycle profits. Remember that $\mathrm{k}$ is the timing of firm b's discount and that firm a's discount is in the first period.

Lemma 2: In the subgame with non-simultaneous timing,

(i) The depths of discounts $\bar{d}_{a}$ and $\bar{d}_{b}$ are characterized by

$$
\begin{aligned}
& \lambda\left(3-\delta^{n}-2 \beta^{n} \delta^{n}\right) \bar{d}_{a}^{2}-2 \theta \delta^{n-k+1}\left(1-\beta^{n} \delta^{n}\right) \bar{d}_{a} \bar{d}_{b}-\lambda y\left(1-\delta^{n}\right)=0 \\
& \lambda\left(3-\delta^{n}-2 \beta^{n} \delta^{n}\right) \bar{d}_{b}^{2}-2 \theta \delta^{k-1}\left(1-\beta^{n} \delta^{n}\right) \bar{d}_{a} \bar{d}_{b}-\lambda y\left(1-\delta^{n}\right)=0
\end{aligned}
$$

(ii) If $k \stackrel{\geq}{=} \frac{n}{2}+1$, then $\bar{d}_{a} \stackrel{\geq}{=} \bar{d}_{b}$.

In order to understand conclusion (ii), consider the case when $\mathrm{k}<\frac{n}{2}+1$. That is, firm a's discount is followed quickly by firm b's. Because firm a can only enjoy the increased demand for a very short time, its incentive for offering discounts is reduced. As a result, a's discount should be smaller than b's. The symmetry in conclusion (ii) (and in Figure 4) around $\mathrm{k}=\frac{n}{2}+1$ should come as no surprise. After all, a cycle is defined arbitrarily in the dynamic process with an infinite time horizon. When $\mathrm{k}>\frac{n}{2}+1$, firm b's discount is closer to firm a's next discount than to the current one. Consequently, the starting and ending points of a cycle can be redefined so that firm b's discount comes first in a cycle, while firm a's discount follows in the (n-k)th period. The conclusion of (ii) can therefore be restated as follows: define the

${ }^{18}$ The Folk Theorem is not applicable here, as it is not a stage game. We can view the equilibrium as a Markov equilibrium because the strategy depends only on the state of the world when an action is taken.

${ }^{19}$ Notice that $\theta$ affects $\mathrm{d}$ through the demand coefficient $\mathrm{x}$, not through parameter $\lambda$. Some people may think that since $x_{t}^{i}=\delta x_{t-1}^{i}+\lambda d_{t}^{i}-\theta d_{t}^{j}$ given $d_{t}^{i}=d_{t}^{j}$, the demand becomes $x_{t}^{i}=\delta x_{t-1}^{i}+(\lambda-\theta) d_{t}$, so the presence of $\theta$ has the effect of reducing the discount coefficient, $\lambda$. Furthermore, since $\mathrm{d}$ increases in $\lambda$, it should in turn decrease in $\theta$. This argument is wrong, as $d_{t}^{i}=d_{t}^{j}$ cannot be assumed a priori. When determining the optimal da, firm a should regard $\mathrm{d}_{\mathrm{b}}$ as given. Consequently, $x_{t}^{i}=\left(\delta x_{t-1}^{i}-\theta d_{b}^{j}\right)+\lambda d_{t}^{i}$. The presence of $\theta$ serves to reduce $x_{t}^{i}$, and we know that d decreases in $\mathrm{x}$.

${ }^{20}$ One might raise the issue of sub game perfection. For fixed $\mathrm{k}$, the timing of actions seems to be well defined: in each cycle, firm a moves first and firm $\mathrm{b}$ moves second. In principle, when choosing its own optimal depth of discount, firm a should anticipate what firm b's response is in the future. With dynamic interaction, however, each firm makes its choice repeatedly. There is no well-defined leader follower relationship when we look beyond one cycle. Therefore, we regard it as a simultaneous-move game: each firm announces its choice of discounts simultaneously at the beginning of each cycle and commits to the discount in that cycle. 
"leader" to be the firm whose discount is closer to the other firm's next discount than to its previous discount. Then the steady state discount of the leader is smaller than that of the follower.

\section{First stage: Equilibrium timing of discounts}

Having derived the steady state profits with various timing arrangements, we are now ready to determine the equilibrium timing of discounts. An analytical solution for non-simultaneous timing is too complicated, so I resort to numerical simulation using the parameter values that have been used throughout the paper: $\lambda=1, \theta=0.5, z=5, \delta$ $=\beta=0.95, \mathrm{n}=6$. Steady state profits of the two firms are calculated for every combination of the timing and the following table is constructed: ${ }^{21}$

This symmetric table has a unique pure-strategy equilibrium, in which both firms offer discounts in the last period of each cycle. Therefore, we draw the following conclusion:

In the dynamic duopoly game, in equilibrium the two firms offer discounts at the same time.

The last graph in Figure 4 reveals that when $\mathrm{k}_{\mathrm{a}}=1$, firm b's profit is maximized at $k_{b}^{*}=2$ : the best response is to offer discounts immediately after its rival does. By doing so, a firm can enjoy the boosted demand for the longest time before its rival's next discount. This is true as long as there is a "later" period in the cycle: When $\mathrm{k}_{\mathrm{a}}=2,3,4,5, k_{b}^{*}=\mathrm{k}_{\mathrm{a}}+1$ (see Table 3). When the rival's discount appears in the last period $\left(\mathrm{k}_{\mathrm{a}}\right.$ $=6$ ), however, there is no period in the same cycle that is later, so firm b's best choice is to offer a discount in the same (last) period. Since the timing game is symmetric, the above best response leads to a unique equilibrium, in which the two firms offer discounts simultaneously.

In principle, the timing game could also have mixed strategy equilibrium, but two forces make it unlikely. First, the purpose of offering discounts is to remind consumers of the existence of the products. Regularity of the discount timing is therefore important. This is different from the incentive of price discrimination, for which unpredictability is a crucial element and consequently randomized strategies fit perfectly. Second, the two firms have a collective incentive to coordinate the timing, as their total profit of $\mathrm{k}_{\mathrm{a}}=\mathrm{k}_{\mathrm{b}}=6$ is the highest among all combinations of the timing and therefore is higher than any weighted average of the payoffs in Table 3. Given the symmetry between the two firms, this means that the pure strategy equilibrium of simultaneous timing Pareto dominates any mixed strategy equilibrium. As long as one firm is able to announce its choice of timing before the other firm does, which is very likely in reality, the coordination can be easily achieved.

In fact, this second force also gives us a hint as to what will happen when the two firms choose different $n$, which is the frequency of discounts. Then their discounts will necessarily be staggered; sometimes a's discount precedes b's, and sometimes b's precedes a's. As we have seen, a firm's discount becomes rather ineffective when followed quickly by its rival's. Over time, the firm's profits fluctuate, but overall, both firms should do worse than when they synchronize their discounts. This gives them strong incentive to choose the same frequency and then coordinate the timing.

Having established simultaneous timing as the only equilibrium in the duopoly dynamic game, we can now study the properties of the equilibrium. Proposition 5 characterizes the steady state of simultaneous timing. We are mainly interested in a comparison between monopoly and duopoly, which is reflected in the presence of parameter $\theta$. We have:

Proposition 6: In the duopoly steady state, $\bar{d}$ increases in $\theta$ and $\bar{x}$ decreases in $\theta$.

Parameter $\theta$ measures the interaction between the two firms. When $\theta$ is larger, the negative impact of one firm's discount on the other firm's demand is larger, so the equilibrium demand level for both firms is lower. Facing lower demands, therefore, each firm needs to offer deeper discounts to compete for consumers.

Since $\theta=0$ represents the case of monopoly, the above Proposition leads to:

Corollary: Compared with monopoly, the duopoly demand is lower, while the discount is deeper.

\section{Conclusion}

This paper provides a new explanation for why price discounts are offered. I suggest that the demand for a firm's product shrinks over time and that the firm periodically uses price discounts to boost the diminishing demand. While it is well known that demand can be stimulated by advertising, the paper's contribution is to show that price reductions can be regarded as a special form of advertising. For a widely used business practice such as price discounts, there are naturally many different explanations. For example, the periodic price reduction in durable goods is explained well by Conlisk et al. [11] and Sobel [12], while consumers' stockpiling behavior for storable goods is modeled by Pesendorfer [13]. I have focused in this paper on non-durable, nonstorable products such as fast foods and services, because these are the places where the existing literature is not able to provide a satisfactory theory ${ }^{22}$. The model works well to explain all of the stylized facts. It also provides some insight into the interaction between firms in a dynamic setup when price discounts are the choice variables.

Notice that the model itself does not need the assumption of a nondurable, non storable good; the basic idea is applicable to any industry. The model's prediction of the optimal pricing pattern has actually

${ }^{21}$ They are steady state profits in each cycle. Lifetime profits are these figures multiplied by $\frac{1}{1-\beta^{n}}$. Also, the profits are gross of the fixed cost, $\mathrm{F}$, (more precisely, firm i's profit is gross of $\beta^{k_{i}-1} F$, where $\mathrm{k}_{\mathrm{i}}$ is the period in which firm i offers its discounts). If the fixed cost is included in the payoffs, the equilibrium of ka $=\mathrm{kb}=6$ is still valid, as offering discounts as late as possible in a cycle becomes even more attractive. On the other hand, when $\mathrm{F}$ is included, there may arise an equilibrium with non- simultaneous timing, but only when the timing of the two firms' discounts differ by exactly half the length of the cycle, e.g., $\mathrm{k}_{\mathrm{a}}=1$ and $\mathrm{k}_{\mathrm{b}}=4$. For this to be an equilibrium, given $\mathrm{k}_{\mathrm{a}}=1$, $\Pi_{\mathrm{b}}\left(\mathrm{k}_{\mathrm{b}}=4\right)$ $=906-\beta^{3} \mathrm{~F}$ needs to be the largest among firm b's profits with other choices of timing. It can be shown that under very mild conditions (say, $\beta \geq \frac{1}{2}$ ), this will never be true.

${ }^{22}$ Foods are mostly perishable within a very short time, so the concern for inventory or storage should not be the primary reason for price discounts as long as the demand is stable and predictable. There may be clearance sales before expiry dates, but that is different from the hi-lo pricing studied in this paper-A discounted burger is as fresh as the ones sold at regular prices (on other days). Besides, selling expiring items at discounted price may run the risk of cannibalization: If the sales are predictable, some people may wait for the sales (admittedly they obtain a lower quality product), which reduces the demand at the regular price. To deal with cannibalization, sellers may commit to not offering any sales for expiring foods. For example, mooncakes are sold once a year in Asian countries before the Mid-Autumn Festival, after which the demand will drop sharply. There is clearly an incentive for retailers to get rid of the unsold mooncakes by selling them at discounted prices. And yet no merchant offers mooncakes for sales after the holiday. They destroy the unsold mooncakes, donate them to charities, or ship them to another country. 
been found in many other industries: periodic price reductions with a long period of a constant high price and a short period of a constant low price for durable goods [1] and non-durable but storable goods [13], as well as simultaneous offerings of price discounts by competing firms $[19,58]$. On the other hand, it is fully possible that several forces could all play a role in generating the pricing pattern of a particular industry. For example, while my model can explain why Burger King offers deep discounts once a week, it does not exclude the element of price discrimination, and the exact timing of discounts may well reflect a concern for peak-load pricing ${ }^{23}$. If that is the case, which theory is more appealing becomes an empirical question. Pashigian [59] and Pashigian and Bowen [60] have done valuable work in this direction.

Although I propose that periodic price reduction is a special form of advertising, there are important differences between the two promotion strategies. Price discounts have the danger of delivering an image of inferior quality, so this strategy should not be utilized in cases when quality is a major concern (new products, fashion clothing, or industries with important vertical product differentiation). The fast food industry is a good place to execute the discounting strategy because the product quality is standard and well known. Consumers have long perceived that $\$ 2.99$ is the normal price for a burger at Burger King, so discounting the price to $\$ 0.99$, while stimulating the demand, will not damage the product image.

Another drawback of price discounts is that competitors are likely to respond with their own price cuts, making the first firm's discounting less effective or even counter-productive. By contrast, advertising has the strategic effect of reducing price competition: When I promote my products with advertising, my customers are less likely to switch to your product. This will make your price cut less effective in luring my customers, so you will cut the price less often or may even raise your own prices, which in turn benefits me.

Of course promotional strategies do not have to be used exclusively. Many discounts in the real world are accompanied by heavy advertising. On the other hand, we do see various advertisements without price discounts. It will be interesting to study under what situation a firm should use advertising and under what situation the firm should use price discounts with advertising. Milgrom and Roberts [18] have analyzed the optimal combination of discounting and advertising for quality signaling. Discounting without advertising is also imaginablefor effective price discrimination.

Other promotional strategies such as public relations, personal selling, direct marketing or sponsorship may also boost consumers' memory. But price discount may also serve the purpose of seconddegree price discrimination [61]: Price-sensitive consumers are more likely to notice the regular price discounts and end up purchasing the product at the lower price, exactly what price discrimination requires. While direct marketing may target particular segments, discrimination is achieved only after the target has been identified first. The beauty of second-degree (i.e., indirect) price discrimination is that the seller does not need to identify or differentiate consumers-consumers differentiate themselves by self-selecting into different pricing deals. Although not modeled in this paper, price discrimination is likely to be a goal by store managers in real life when they choose marketing strategies, and price discounts have the advantage of achieving memory stimulation and price discrimination simultaneously.

\section{Appendix}

\section{A Proof of Proposition 1}

If a normal price, $\mathrm{p}_{\mathrm{t}}$, should deviate from the single-period optimal level, $\mathrm{p}_{\mathrm{m}}$, the concern must be the indirect effect. I distinguish between two cases: $\mathrm{p}_{t}^{n n}$ (the next period price is also normal) and $\mathrm{p}_{t}^{n d}$ (the next period price is discounted). When $\mathrm{p}_{\mathrm{t}}=\mathrm{p}_{t}^{n n}$, the indirect effect is zero, so in equilibrium $\mathrm{p}_{t}^{n n}=\mathrm{p}_{\mathrm{m}}$ for every $\mathrm{t}$.

As for $p_{t}^{\text {nd }}$, if $p_{t}^{\text {nd }}=\mathrm{p}_{\mathrm{m}}$ for every $\mathrm{t}$, the proof is finished. Suppose that in an equilibrium, $p_{t}^{n d} \neq p_{m}$ for at least one t. Because $p_{\mathrm{r}}$ is the weighted average of every $p_{t}^{n d}$ and many $p_{t}^{n n}$, we have $\operatorname{mint}\left\{p_{t}^{\text {nd }}\right\}<\mathrm{p}_{\mathrm{r}}<\operatorname{maxt}\{$ $\left.p_{t}^{n k}\right\}$. Let $\mathrm{j}\left\{\arg \operatorname{mint}\left\{p_{t}^{n d}\right\}\right\}$ and $\mathrm{k}\left\{\arg \operatorname{maxt}\left\{p_{t}^{n d}\right\}\right\}$.

If $\mathrm{p}_{\mathrm{r}} \geq \mathrm{p}_{\mathrm{m}}$, then $p_{k}^{n d}>\mathrm{p}_{\mathrm{r}} \geq \mathrm{p}_{\mathrm{m}}$. Then, the monopolist can earn a higher profit by slightly lowering $p_{k}^{\text {nd }}$, because $\mathrm{rk}+1=\min \left\{\mathrm{p}_{\mathrm{r}}, p_{j}^{\text {nd }}\right\}=$ $\mathrm{p}_{\mathrm{r}}$ is not affected by $p_{k}^{n d}$, and the profit in period $\mathrm{k}$ is decreasing in $p_{k}^{n d}$ when $p_{k}^{\text {nd }}>\mathrm{p}_{\mathrm{m}}$.

If $\mathrm{p}_{\mathrm{r}}<\mathrm{p}_{\mathrm{m}}$, then $p_{j}^{\text {nd }}<\mathrm{p}_{\mathrm{r}}<\mathrm{p}_{\mathrm{m}}$. Then $\mathrm{r}_{\mathrm{j}+1}=\min \left\{\mathrm{p}_{\mathrm{r}}, p_{j}^{n d}\right\}=p_{j}^{\text {nd }}$. The profit in period $\mathrm{j}$ is increasing in $p_{j}^{n d}$ when $p_{j}^{n d}<\mathrm{p}_{\mathrm{m}}$. The profit in the next period, $\pi_{j+1}=q_{j+1}\left(p_{j+1}-c\right)-F=\left(\delta x_{j}+\lambda d_{j+1}\right)\left(\mu-p_{j+1}\right)\left(p_{j+1}-c\right)-F$, is increasing in $\mathrm{p}_{\mathrm{j}+1}$ for fixed $\mathrm{d}_{\mathrm{j}+1}>0$, as $\mathrm{p}_{\mathrm{j}+1}=p_{j}^{n d}-\mathrm{dj}+1<p_{j}^{n d}<\mathrm{p}_{\mathrm{m}}$. But $\mathrm{p}_{\mathrm{j}+1}=p_{j}^{n d}-\mathrm{dt}+1$ increases in $p_{j}^{n d}$, so in turn $\pi_{\mathrm{j}+1}$ also increases in $p_{j}^{n d}$ . Therefore the firm could have enjoyed a higher profit in both period $\mathrm{j}$ and period $(\mathrm{j}+1)$ by slightly increasing $p_{j}^{\text {nd }}$, while the profits in all the following periods are either not affected (when period $(j+2)$ is a normal period) or positively affected (when period $(j+2)$ is a discount period), as the reference price in period $(j+2), r_{j+2}=p_{j+1}$, is higher, while the demand coefficient, $x_{j+2}=\delta x_{j+1}+\lambda d_{j+2}=\delta^{2} x_{j}+\delta \lambda d_{j+1}+\lambda d_{j+2}$, is the same when $d_{j+1}$ and $d_{j+2}$ are both fixed.

In summary, $p_{j}^{\text {nd }}$ must equal to $\mathrm{pm}$ for every $\mathrm{t}$ in any equilibrium. Combined with the fact that $p_{t}^{n n}=\mathrm{p}_{\mathrm{m}}$ for every $\mathrm{t}$, this leads to the conclusion that all normal prices are the same. Moreover, they are all equal to $\mathrm{p}_{\mathrm{m}}$. As a result, $\mathrm{p}_{\mathrm{r}}=\mathrm{p}_{\mathrm{m}}$.

\section{B Proof of Proposition 2}

In the dynamic programming problem (3), let $g=\delta^{\mathrm{n}} \mathrm{x}+\delta \lambda d$. Then, the first-order condition with respect to the choice variable, $d$, gives:

$$
\beta^{n-1}\left[\lambda\left(z^{2}-d^{2}\right)-2 \lambda d^{2}-2 \delta^{n-1} x d\right]+\beta^{n} V^{\prime}(g) \lambda \delta=0
$$

The envelope equation associated with the state variable, $\mathrm{x}$, leads to:

$$
V^{\prime}(x)=y-\beta^{n-1} \delta^{n-1} d^{2}+\beta^{n} \delta^{n} V^{\prime}(g)
$$

From (14), solve for the expression of $V^{\prime}(g)$, which is then plugged into (15) to get:

$$
V^{\prime}(x)=y-\beta^{n-1} \delta^{n-1} d^{2}+\beta^{n-1} \delta^{n-1}\left(3 d^{2}-z^{2}+\frac{2 \delta^{n-1} x d}{\lambda}\right)
$$

Now, use variable $\mathrm{g}=\delta^{\mathrm{n}} \mathrm{x}+\delta \lambda d$ as a substitute for $\mathrm{x}$ in equation (16) to get the derivative of the value function evaluated at g:

$$
V^{\prime}(g)=y-\beta^{n-1} \delta^{n-1} d^{2}+\beta^{n-1} \delta^{n-1}\left(3 d^{2}-z^{2}+\frac{2 \delta^{n-1}\left(\delta^{n} x+\delta \lambda d\right) d}{\lambda}\right)
$$

${ }^{23}$ The discounts on Tuesdays by Hong Kong movie theatres may be partly explained by the fact that many people go to horse racing on Wednesdays while new movies are always released on Thursdays. 
Plug (17) into (14) to get

$H(d)=\lambda\left(2 \beta^{n} \delta^{n}+2 \beta^{n} \delta^{2 n}-3\right) d^{2}-2 \delta^{n-1} x\left(1-\beta^{n} \delta^{2 n}\right) d+\lambda y=0$

Using $\varphi$ and $\phi$ specified in the proposition, (18) becomes

$H(d)=\lambda \varphi d^{2}-2 x \phi d+\lambda y=0$

Notice that $\lambda, \mathrm{x}, \phi, \mathrm{y}>0$, but $\varphi$ could be either positive or negative. Out of the two solutions of $d$ in equation (19), only the one given in the proposition is optimal.

One can easily verify that $\mathrm{d}^{*}>0$. When $\mathrm{x}^{2} \geq\left(\varphi \lambda^{2} \mathrm{y}\right) / \phi^{2}$, the term within the square root is non-negative so that $\mathrm{d}^{*}$ is well defined. Otherwise, $H(d)$ is positive for every $d$, and $d$ should take the highest possible value, namely $\mathrm{p}_{\mathrm{m}}$.

For the requirement that $\mathrm{d}^{*} \leq \mathrm{p}_{\mathrm{m}}$, observe that $\mathrm{d}^{*}$ depends on $\mathrm{z}$, which is $(\mu-c) / 2$, while $\mathrm{p}_{\mathrm{m}}=(\mu+\mathrm{c}) / 2$. For any $\mathrm{p}_{\mathrm{m}}, \mathrm{z}$ can be made arbitrarily small so that $\mathrm{d}^{*}$ will be close to zero and $\mathrm{d}^{*} \leq \mathrm{p}_{\mathrm{m}}$ will always be satisfied.

\section{Proof of Proposition 3}

In any steady state, $\mathrm{x}=\mathrm{g}(\mathrm{x}, \mathrm{d}(\mathrm{x}))=\delta^{\mathrm{n}} \mathrm{x}+\delta \lambda \mathrm{d}$. Therefore,

$x=\frac{\lambda \delta d}{1-\delta^{n}}$

By plugging (20) into the expression $\mathrm{H}(\mathrm{d})=0$ in equation (18), the steady states $\bar{x}$ and $\bar{d}$ can be found as shown in the Proposition. Notice that $\bar{d}$ depends only on $\mathrm{z}=(\mu-\mathrm{c}) / 2$ and therefore is independent of the requirement $\bar{d} \leq \mathrm{p}_{\mathrm{m}}=(\mu+\mathrm{c}) / 2$. For simplicity, let us ignore the unlikely case where $\bar{d}>\mathrm{p}_{\mathrm{m}}$.

Recall from Proposition 2 that in order for $\mathrm{d}=\mathrm{d}^{*}, \mathrm{x} 2$ must be no less than $\left(\varphi \lambda^{2} y\right) / \phi^{2}$. It turns out that this requirement is always satisfied at $\mathrm{x}=\bar{x}$ :

$$
\bar{x}^{2}-\frac{\varphi \lambda^{2} y}{\phi^{2}}=\frac{\lambda^{2} y}{\phi^{2}} \frac{\left(3+\beta^{n} \delta^{3 n}-2 \delta^{n}-2 \beta^{n} \delta^{n}\right)^{2}}{\left(1-\delta^{n}\right)\left(3-\delta^{n}-2 \beta^{n} \delta^{n}\right)} \geq 0
$$

Expression $\mathrm{H}(\mathrm{d})=0$ of equation (19) fully characterizes the optimal choice of $\mathrm{d}^{*}$. There is a one-for-one mapping between the state variable, $\mathrm{x}$, and the choice variable, $\mathrm{d}^{*}$. From $\mathrm{H}\left(\mathrm{d}^{*}\right)=0$,

$\mathrm{x}$ can be expressed as a function of $\mathrm{d}^{*}$ :

$$
x\left(d^{*}\right)=\frac{\lambda}{2 \phi}\left(\varphi d^{*}+\frac{y}{d^{*}}\right)
$$

Consequently, the state variable of the next cycle, g, can also be expressed as a function of the choice variable, $\mathrm{d}^{*}$, in the current cycle:

$$
g\left(d^{*}\right)=\delta^{n} x+\delta \lambda d^{*}=\frac{\lambda \delta^{n}}{2 \phi}\left(\varphi d^{*}+\frac{y}{d^{*}}\right)+\delta \lambda d^{*}
$$

From the discussion of comparative statics, we know that $\mathrm{d}^{\star}$ decreases in $\mathrm{x}: x\left(\mathrm{~d}^{*}\right)<0$. Thus,

$$
g^{\prime}\left(d^{*}\right)=\delta^{n} x^{\prime}\left(d^{*}\right)+\delta \lambda>\delta^{n} x^{\prime}\left(d^{*}\right)>x^{\prime}\left(d^{*}\right)
$$

At $(\bar{x}, \bar{d})$, the slope of $\mathrm{g}\left(\mathrm{d}^{*}\right)$ is negative:

$$
g^{\prime}(\bar{d})=\frac{\lambda \delta^{n}}{2 \phi}\left(\varphi-\frac{y}{\bar{d}^{2}}\right)+\delta \lambda=-\frac{\lambda \delta^{n}}{\phi} \frac{\left(2-\delta^{n}\right)\left(1-\beta^{n} \delta^{n}\right)}{1-\delta^{n}}<0
$$

The two curves, $\mathrm{x}\left(\mathrm{d}^{*}\right)$ and $\mathrm{g}\left(\mathrm{d}^{*}\right)$, cross each other at $(\bar{x}, \bar{d})$, at which point the slopes of both curves are negative.

$\mathrm{d}^{*}$ is monotonically decreasing in $\mathrm{x}$. Corresponding to $\mathrm{x}=0$, there is a maximum $d=d_{m}=\sqrt{-(y / \varphi)}$. In general $\mathrm{g}\left(\mathrm{d}^{*}\right)$ is $\mathrm{U}$-shaped. $\mathrm{g}\left(\mathrm{d}^{*}\right)$ achieves its maximum slope at $\mathrm{d}_{\mathrm{m}}$ :

$$
\begin{aligned}
& g^{\prime}\left(d_{m}\right)=\frac{\lambda \delta^{n}}{2 \phi}\left(\varphi-\frac{y}{d_{m}^{2}}\right)+\delta \lambda \\
& =\frac{\lambda \delta^{n} \varphi}{\phi}+\delta \lambda=\frac{\lambda \delta^{n}}{\phi}\left(2 \beta^{n} \delta^{n}+\beta^{n} \delta^{2 n}-2\right)
\end{aligned}
$$

The slope $g^{\prime}\left(d_{m}\right)$ could be either positive or negative. However, $\mathrm{g}\left(\mathrm{d}_{\mathrm{m}}\right)$ is never greater than $\bar{x}$ :

$$
\begin{aligned}
& g\left(d_{m}\right)=\delta^{n} x+\delta \lambda d_{m} \\
& \left.=\lambda \delta d_{m} \text { (because } \mathrm{d}=\mathrm{d}_{\mathrm{m}} \text { implies } \mathrm{x}=0\right) \\
& =\lambda \delta \sqrt{-(y / \varphi)} \\
& \leq \lambda \delta z \sqrt{\frac{\gamma}{1-\delta^{n}}}=\bar{x} .
\end{aligned}
$$

The dynamics of the system are represented by the transition from $x\left(d^{*}\right)$ to $g\left(d^{*}\right)$. The two variables are brought together by $\mathrm{d}^{*}$ as a linkage. Figure 2 shows the only two possible cases of the dynamic system: $g^{\prime}\left(d_{m}\right)<0$ and $g^{\prime}\left(d_{m}\right)>0$.

(1) $g^{\prime}\left(d_{m}\right)<0$. Both $\mathrm{x}(\mathrm{d})$ and $\mathrm{g}(\mathrm{d})$ are monotonically decreasing in $\mathrm{d}$, and $\mathrm{x}(\mathrm{d})$ has a steeper slope than $\mathrm{g}(\mathrm{d})$ for any valid $\mathrm{d}$. Starting from an arbitrary $x_{1}$, the firm chooses $d_{1}$, which is found on curve $x(d)$. Then corresponding to the same $d_{1}, g_{1}$ is found from the $g(d)$ curve. The transition is a mapping from $\mathrm{x}_{1}$ to $\mathrm{g}_{1}$. In the next round $\mathrm{g}_{1}$ becomes $\mathrm{x}_{2}$ and the whole process repeats itself. It is clear from the picture that the system converges monotonically to $(\bar{x}, \bar{d})$

(2) $g^{\prime}\left(d_{m}\right)>0$. Starting from any $\mathrm{x}$, the system again converges monotonically to $(\bar{x}, \bar{d})$.

\section{Proof of Proposition 4}

The objective function is given in equation (6), and the choice variable is $\mathrm{s}$. The first-order condition is

$$
\Pi^{\prime}(s)=\frac{2 \lambda z^{3}}{\sqrt{\left(1-\delta^{2}\right)^{3}}}\left(6-s^{2}\right) \sqrt{\frac{(1+s)^{3}}{(1-s)^{3}(3+2 s)^{5}}}-\frac{F}{(1-s)^{2}}=0
$$

With $\mathrm{G}$ and $\mathrm{u}(\mathrm{s})$ defined as in the proposition, the above equation becomes $\mathrm{F}=\mathrm{Gu}\left(\mathrm{s}^{\star}\right) \cdot u^{\prime}(\mathrm{s})$ is always negative for any $\mathrm{s} \in(0,1)$, so the second-order condition is always satisfied.

Figure 5 shows $\mathrm{u}$ as a function of $\mathrm{s}$. It is clear from the picture that the optimal s (and thus the optimal $\mathrm{n}$ ) is found at the intersection of $\mathrm{u}(\mathrm{s})$ and $\frac{F}{G}=\frac{F}{2 \lambda z^{3}}\left(1-\delta^{2}\right)^{\frac{3}{2}}$. When $\mathrm{F} / \mathrm{G}>\frac{2}{9} \sqrt{3}=0.385$, there is no intersection $\Leftrightarrow \delta \mathrm{n}^{*}=\mathrm{s}^{\star}=0 \Leftrightarrow \mathrm{n}^{*}=\infty$. The fact that $\mathrm{n} \geq 2$ (remember that discounts are never offered in consecutive periods) leads to the other boundary result in (iii).

Since $n^{*}$ decreases in $s^{*}$, it is straightforward to verify the comparative statics from the picture.

\section{E Proof of Lemma 1}

Regarding equation (8), for firm a, there is a first-order condition with respect to the choice variable $\mathrm{d}_{\mathrm{a}}$ :

$$
\lambda\left(y-d_{a}^{2}\right)-2\left(x_{a}+\lambda d_{a}-\theta d_{b}\right) d_{a}+\beta^{n}\left[\delta^{n} \lambda \frac{\partial V}{\partial x_{a}}\left(g_{a}, g_{b}\right)-\delta^{n} \theta \frac{\partial V}{\partial x_{b}}\left(g_{a}, g_{b}\right)\right]
$$

There are two envelope equations, corresponding to the two state 
variables:

$$
\begin{aligned}
& \frac{\partial V}{\partial x_{a}}\left(x_{a}, x_{b}\right)=\left(y-d_{a}^{2}\right)+\beta^{n} \delta^{n} \frac{\partial V}{\partial x_{a}}\left(g_{a}, g_{b}\right) \\
& \frac{\partial V}{\partial x_{b}}\left(x_{a}, x_{b}\right)=\beta^{n} \delta^{n} \frac{\partial V}{\partial x_{b}}\left(g_{a}, g_{b}\right)
\end{aligned}
$$

From equations (22) and (23), express the two partial derivatives evaluated at $\left(\mathrm{g}_{\mathrm{a}}, \mathrm{g}_{\mathrm{b}}\right)$ in terms of those evaluated at $\left(\mathrm{x}_{\mathrm{a}}, \mathrm{x}_{\mathrm{b}}\right)$, and plug the results into equation (21),

$$
\lambda \frac{\partial V}{\partial x_{a}}\left(x_{a}, x_{b}\right)-\theta \frac{\partial V}{\partial x_{b}}\left(x_{a}, x_{b}\right)=2 \lambda d_{a}^{2}+2 x_{a} d_{a}-2 \theta d_{a} d_{b}
$$

Using $g_{a}$ to substitute for $x_{a}$ in the right-hand side of the above equation, we get the left-hand side expression evaluated at $\left(\mathrm{g}_{\mathrm{a}}, \mathrm{g}_{\mathrm{b}}\right)$ :

$$
\lambda \frac{\partial V}{\partial x_{a}}\left(g_{a}, g_{b}\right)-\theta \frac{\partial V}{\partial x_{b}}\left(g_{a}, g_{b}\right)=2 \lambda d_{a}^{2}+2 d_{a} \delta^{n}\left(x_{a}+\lambda d_{a}-\theta d_{b}\right)-2 \theta d_{a} d_{b}
$$

Plug (25) into equation (21), and the best response function for firm a emerges as an implicit function of $\mathrm{d}_{\mathrm{a}}$ and $\mathrm{d}_{\mathrm{b}}$ :

$$
\begin{aligned}
\lambda\left(-3+2 \beta^{n} \delta^{n}+2 \beta^{n} \delta^{2 n}\right) d_{a}^{2}+ & 2 \theta\left(1-\beta^{n} \delta^{n}-\beta^{n} \delta^{2 n}\right) \\
& d_{a} d_{b}-2 x_{a}\left(1-\beta^{n} \delta^{2 n}\right) d_{a}+\lambda y=0
\end{aligned}
$$

which is the expression in the Lemma.

When $\mathrm{x}_{\mathrm{a}}$ is switched with $\mathrm{x}_{\mathrm{b}}$ in equation (26), and at the same time $d_{a}$ is switched with $d_{b}$, firm b's best response function will emerge as:

$$
\begin{aligned}
\lambda\left(-3+2 \beta^{n} \delta^{n}+2 \beta^{n} \delta^{2 n}\right) & d_{b}^{2}+2 \theta\left(1-\beta^{n} \delta^{n}-\beta^{n} \delta^{2 n}\right) \\
& d_{a} d_{b}-2 x_{b}\left(1-\beta^{n} \delta^{2 n}\right) d_{b}+\lambda y=0
\end{aligned}
$$

\section{F Proof of Proposition 5}

The steady state should be characterized by four equations: the two best response equations, (26) and (27), and two steady state transition equations:

$$
g_{a}=\delta\left(x_{a}+\lambda d_{a}-\theta d_{b}\right)=x_{a} ; g_{b}=\delta\left(x_{b}+\lambda d_{b}-\theta d_{a}\right)=x_{b}
$$

From (28), we solve

$$
\bar{x}_{a}=\frac{\delta^{n}\left(\lambda \overline{d_{a}}-\theta \overline{d_{b}}\right)}{1-\delta^{n}} \text { and } x_{b}=\frac{\delta^{n}\left(\lambda \bar{d}_{b}-\theta \bar{d}_{a}\right)}{1-\delta^{n}}
$$

Take the difference between equations (26) and (27) and plug in (29). We have:

$$
\frac{\lambda\left(3-\delta^{n}-2 \beta^{n} \delta^{n}\right)}{1-\delta^{n}}\left(\bar{d}_{a}^{2}-\bar{d}_{b}^{2}\right)=0
$$

thus $\bar{d}_{a}=\bar{x}_{b}$. Consequently $\bar{x}_{a}=\bar{x}_{b}$. Drop the subscript. Plugging (29) into either (26) or (27), we get the steady state discount and demand in the Proposition. Notice that the denominator in the expression

$$
\begin{aligned}
& \sigma=\lambda\left(3-\delta^{n}-2 \beta^{n} \delta^{n}\right)-2 \theta\left(1-\beta^{n} \delta^{n}\right) \\
& >\lambda\left(3-\delta^{n}-2 \beta^{n} \delta^{n}\right)-2 \lambda\left(1-\beta^{n} \delta^{n}\right) \\
& =\lambda\left(1-\delta^{n}\right)>0
\end{aligned}
$$

so that the expression is well defined.

\section{G Proof of Lemma 2}

In the steady state, the demand coefficient for firm a at the beginning of the next cycle, $g_{a}=\delta^{n}\left(x_{a}+\lambda d_{a}\right)-\theta \delta^{n-k+1} d_{b}$, should equal to that of the previous cycle, $x_{a}$. From this equation, we can solve $\bar{x}_{a}=\frac{\lambda \delta^{n} \bar{d}_{a}-\theta \delta^{n-k+1} \bar{d}_{b}}{1-\delta^{n}}$

Similarly,

$\bar{x}_{b}=\frac{\lambda \delta^{n-k+1} \bar{d}_{b}-\theta \delta^{n} \bar{d}_{a}}{1-\delta^{n}}$

These two expressions are then plugged into equations (10) and (11) to get the expressions in the Lemma.

Taking the difference between the two equations (12) and (13), we find that $\bar{d}_{a}^{2}-\bar{d}_{b}^{2}$ has the

same sign as $\delta^{\mathrm{n}-\mathrm{k}+1}-\delta^{\mathrm{k}-1}$. When, $\mathrm{k}=\frac{n}{2}+1 \quad \delta^{\mathrm{n}-\mathrm{k}+1}=\delta^{\mathrm{k}-1}$ so $\bar{x}=\bar{d}_{b}$. When $\mathrm{k} \gtrless \frac{n}{2}+1 \delta^{\mathrm{n}-\mathrm{k}+1} \gtrless \delta^{\mathrm{k}-1}$ so $\bar{d}_{a} \gtrless \bar{d}_{b}$.

\section{H Proof of Proposition 6}

We know by direct observation that $\bar{d}$ increases in $\theta$.

$$
\begin{aligned}
& \frac{\partial \bar{x}}{\partial \theta}=\delta^{n}\left[\lambda\left(\delta^{n}+\beta^{n} \delta^{n}-2\right)+\theta\left(1-\beta^{n} \delta^{n}\right)\right] \sqrt{\frac{\lambda y}{\sigma^{3}\left(1-\delta^{n}\right)}} \\
& \text { But } \lambda\left(\delta^{n}+\beta^{n} \delta^{n}-2\right)+\theta\left(1-\beta^{n} \delta^{n}\right) \\
& \qquad \lambda\left(\delta^{n}+\beta^{n} \delta^{n}-2\right)+\lambda\left(1-\beta^{n} \delta^{n}\right)=\lambda\left(\delta^{n}-1\right)<0
\end{aligned}
$$

Therefore, $\bar{x}$ decreases in $\theta$.

\section{Acknowledge}

I would like to thank Leonard Cheng, Daniel Graham, Ping Lin, Jae Hyon Nahm, Larry Qiu, Tridip Ray, David Ridley, Keun Kwan Ryu, Nikolaos Vettas, Changqi Wu, and Kangoh Yi for helpful discussions and comments.

\section{References}

1. Gerstner E (1985) Sales: demand-supply variation or price discrimination? J Eco Busn 37: 171-182.

2. Shilony Y (1977) Mixed pricing in oligopoly. J Econ Theory 14: 373-388

3. Varian HR (1980) A model of sales. Am Econ Rev 70: 651-659.

4. Narasimhan C (1988) Competitive promotional strategies. J Bus 61: 427-449.

5. Hess JD, Gerstner E (1987) Loss leader pricing and rain check policy. Marketing Science 6: 358-374.

6. Lal R, Rao R (1997) Supermarket competition: the case of everyday low pricing. Marketing Science 16: 60-80.

7. Gerstner E, Hess JD (1990) Can bait and switch benefit consumers? Marketing Science 9: 114-124.

8. Lazear EP (1986) Retail pricing and clearance sales. Am Econ Rev 76: 14-32.

9. Blattberg RC, Eppen GD, Lieberman J (1981) A theoretical and empirical evaluation of price deals for consumer nondurables. Journal of Marketing 45:116-129.

10. Jeuland AP, Narasimhan C (1985) Dealing-temporary price cuts-by seller as a buyer discrimination mechanism. J Bus 58: 295-308.

11. Conlisk J, Gerstner E, Sobel J (1984) Cyclic pricing by a durable goods monopolist. Q J Econ 99: 489-505.

12. Sobel J (1984) The timing of sales. Rev Econ Stud 51: 353-368.

13. Pesendorfer M (2002) Retail sales: A study of pricing behavior in supermarkets. J Bus 75: 33-66.

14. Stokey NL (1979) Intertemporal price discrimination. Q J Econ 93: 355-371.

15. Varian HR (1989) Price discrimination. Handbook of Industrial Organization 1 : 597-654.

16. Gerstner E (1986) Peak load pricing in competitive markets. Economic Inquiry 24: 349-361.

17. Warner EJ, Barsky RB (1995) The timing and magnitude of retail store markdowns: Evidence from weekends and holidays. Q J Econ 110: 321-352. 
18. Milgrom P, Roberts J (1986) Price and advertising signals of product quality. J Polit Econ 94: 796-821.

19. Doyle C (1986) Intertemporal price discrimination, uncertainty and introductory offers. The Economic Journal 96: 71-82.

20. Villas-Boas JM (2004) Price cycles in markets with customer recognition. Rand J Econ 35: 486-501.

21. Deaton A (1992) Understanding consumption. Oxford University Press.

22. Katona G (1951) Psychological analysis of economic behavior. McGraw-Hill, New York.

23. Lahiri A, Puhakka M (1998) Habit persistence in overlapping generations economies under pure exchange. J Econ Theory 78: 176-186.

24. Scitovsky T (1992) The joyless economy: the psychology of human satisfaction. Oxford University Press.
25. Blattberg RC, Neslin SA (1990) Sales promotion: Concepts, methods and strategies. Prentice Hall.

26. Slade ME (1998) Optimal pricing with costly adjustment: Evidence from retailgrocery prices. Rev Econ Stud 65: 87-107.

27. Stokey NL, Lucas RE, Prescott EC (1989) Recursive methods in economic dynamics. Harvard University Press, Cambridge.

28. Rosenthal RW (1982) A dynamic model of duopoly with customer loyalties. J Econ Theory 27: 69-76.

29. Lal R (1990) Price promotions: limiting competitive encroachment. Marketing Science 9: 247-262.

30. Pashigian BP (1988) Demand uncertainty and sales: A study of fashion and markdown pricing. Am Econ Rev 78: 936-953.

31. Pashigian BP, Bowen B (1991) Why are products sold on sale: explanations of pricing regularities. Q J Econ 106: 1015-1038. 